\title{
DESIGNING DIGITAL TECHNOLOGY FOR SERVICE WORK: SYSTEMATIC AND PARTICIPATORY APPROACH
}

\author{
Watanabe, Kentaro; Fukuda, Ken \\ National Institute of Advanced Industrial Science and Technology
}

\begin{abstract}
Digital technology is dramatically changing our life, industry, and society. Recent evolution of digital technology is expected to significantly impact service work, such as healthcare and social welfare. Meanwhile, an insufficient understanding of service work and workers' needs leads to the failure of technology development and integration. To make digital technology better fit to values and work practices of service workers, various studies have been conducted, especially in the field of participatory design, interaction design, and service design. However, the contribution of engineering design to this topic is still limited. This paper proposes an engineering design approach to design digital technology for better integration in service work. This study combines a modelling method to represent specifications of digital technology and the participatory approach in alignment with the changing service work and workers' values. A case study of the mobile application system for elderly-care professionals is introduced to exemplify the effectiveness of the proposed method. This study intends to foster innovation of service work through digitalization.
\end{abstract}

Keywords: Digital technology, Service design, Design engineering, Collaborative design

\section{Contact:}

Watanabe, Kentaro

National Institute of Advanced Industrial Science and Technology

Human Augmentation Research Center

Japan

kentaro.watanabe@aist.go.jp

Cite this article: Watanabe, K., Fukuda, K. (2019) 'Designing Digital Technology for Service Work: Systematic and Participatory Approach', in Proceedings of the 22nd International Conference on Engineering Design (ICED19), Delft, The Netherlands, 5-8 August 2019. DOI:10.1017/dsi.2019.151 


\section{INTRODUCTION}

Digital technology such as mobile devices, human sensing, Internet of Things (IoT), artificial intelligence (AI), and robotics is dramatically changing our life, industry, and society. Recent evolution of digital technology is expected to significantly impact service work, such as healthcare, social welfare, hotel, and retail stores (D'Emidio et al., 2015). Service work, which requires intimate human-to-human interactions, was traditionally difficult to support with conventional information and communication technology (ICT). However, recent digital technology has enabled service providers and workers to collect data directly from workplaces, as well as to customize and even automatize service provision. Digitalization using these technologies has brought a strong expectation towards innovation in such service work (D'Emilio et al., 2015). For example, elderly care is considered a major target of service innovation through digitalization (Siegel et al., 2014). Various technological applications have been developed and introduced, such as behaviour sensors to monitor the elderly at bed, care robotics for both the elderly and caregivers, and information systems to record the elderly's status.

Meanwhile, digital technology is pervasive and has a strong impact on the workstyle. Generally, an insufficient understanding of service work and workers' needs leads to the failure of technology development and integration (Leikas, 2014). To make digital technology better fit to values and work practices of service workers, various studies have been conducted, especially in the field of participatory design, interaction design, and service design (Bue Lintho and Nes Begnum, 2018; Pérez García and Saffón López, 2018). However, the contribution of engineering design to this topic is still limited.

This paper proposes an engineering design approach to design digital technology for better integration in service work. This study combines a modelling method to determine specifications of digital technology and the participatory approach in alignment with the changing service work and workers' values. It intends to foster innovation of service work through digitalization.

The rest of this paper is organized as follows. The characteristics of digital technologies and the challenges of their design are introduced in Section 2. The proposed design method is represented in Section 3. A case to which the proposed method is applied, and the research method are explained in Section 4. The research result is introduced in Section 5. After providing a discussion on the result in Section 6, the concluding remarks are provided in Section 7.

\section{DIGITAL TECHNOLOGY AND SERVICE INNOVATION}

\subsection{Digitalization of service work}

Service work by humans was traditionally a minor target of technological support, compared to manufacturing workplaces and business offices. Technologies including information technology used to be huge, immobile, and difficult to control. Therefore, workers needed to adapt their work processes to the requirements of technologies, such as an automated production line and an office PC. However, it was difficult to apply this approach to service work, because workers, especially front-line workers, could not stay at the same place for a long time during their work.

The recent evolution of digital technology has started changing this situation. Mobile devices such as smartphones enable service workers to access the required information whenever and wherever they want to. Human sensing and IoT devices can collect customer and worker data and even provide realtime feedback to them. Furthermore, machine-learning-based AI technologies and service robotics are gradually applicable to support, or even substitute, some types of work which require long-term experience. Digitalization in service work by using these technologies is expected to increase service productivity and to reduce the burden of service workers (D'Emilio et al., 2015).

\subsection{Challenges in innovating service work through digitalization}

In contrast to the strong expectation towards service innovation through digitalization, there are several challenges to overcome for promoting digitalization in services.

\subsubsection{Diversity in values of service workers}

Traditionally, efficiency at work, as value from the management perspective, and safety at work, as the ergonomic perspective, were emphasized when new technologies were implemented at work (Salvendy, 2012). These values are still important, but recently, a wider variety of values have been 
emphasized more. For example, wellbeing at work has been emphasized by various international organizations such as International Labour Organization (ILO, 2018) and European Agency for Safety and Health at Work (EU-OSHA, 2013). Compared to the traditional ergonomic measures towards physical and mental loads of service workers, the concept of wellbeing at work emphasizes the positive influence on workers, which includes job autonomy, employability, involvement, comfort, and work-life balance (EU-OSHA, 2013). Wellbeing has been a major topic in organizational design (Pot, 2017), and recently, has attracted further attention in the field of information system design (Calvo and Peters, 2015). In the domain of positive computing, it is emphasized how to improve wellbeing through the use of digital technology (Calvo and Peters, 2015).

As the impact of digital technology at work is being emphasized, technology ethics is also becoming a keen issue. Moral value is highlighted, especially for applying AI and service robotics to service work. Privacy is a typical concern related to digital technologies (Stahl and Wright, 2018). While it has become easy to collect and share data related to services by using mobile devices and sensors, these data can also be used for unintentional purposes and may be leaked through cyberattack. In addition, a series of studies on computers and ethics have pointed out various human values to be taken care of, such as ownership of property, freedom from bias, trust, autonomy, and courtesy (Friedman et al., 2013). Recently, social concerns related to AI and robotics have been increasing, such as job loss and humanity crisis. Corresponding to the anxiety, the discussion on ethical values to be considered when designing and developing digital technologies, has become active, which can be seen in Asilomar AI Principles, for example (Future of Life, 2017).

Moreover, values related to digital technology also need to be considered from the international viewpoint. Digital technology is transferrable to different countries. Values for users depend on institutional background at site (Akaka et al., 2013). In the elderly care setting, for example, local lifestyle of the elderly, work culture, and national care policy need to be investigated when digital technologies are implemented (Djellal and Gallouj, 2006, Watanabe et al., 2018).

\subsubsection{Interaction between digital technology and service work}

Another challenge is the interaction between digital technology and service work. Service work is affected and changed through the integration of technology. Requests for change at work are not welcomed by workers, even if the change is intended for their values (Pot, 2017). Technology implementation tends to bring negative impacts to service workers, such as additional tasks to input information into the installed system. The negative impact can be temporary but causes resistance by service workers. Furthermore, emerging technologies such as AI and robotics are considered to bring a fundamental change in service work, which arouses fear among service workers.

For better integration of digital technologies into services, it is important to understand, and even redesign, service work corresponding to the technology (Edvardsson and Olsson, 1996). In addition, technologies should be well adapted to service work. Actually, digital technology is adaptive to different use cases owing to its programmability. It is beneficial to (re)design the specification of digital technology in relation with changing service work.

\subsection{Existing studies and contribution of engineering design}

Several design studies have tackled the aforementioned challenges as described below. For example, value-sensitive design is an approach to design information systems according to the values of users (Friedman et al., 2013). In value-sensitive design, ethical value is the major target to be satisfied when developing information systems. For this, integration of users into the design process is important to harmonize technologies into their life and work. This has been emphasized in several studies, such as participatory design (Greenbaum and Kyng, 1991) and positive computing (Calvo and Peters, 2015). New Service Development (Fitzsimmons and Fitzsimmons, 1999) and service design (Stickdorn and Schneider, 2012) are also research domains to focus on service work and artefacts used in the work. Watanabe et al. (2015) specifically highlighted employees' role in designing the usage of technologies. However, these studies do not provide a scheme to represent the specification of technological features and service work. Systematic modelling schemes in engineering design are beneficial for developing an adequate technology precisely for service work (Watanabe et al., 2013). Regarding the systematic modelling scheme, several studies on product-service systems (PSSs) (Goedkoop et al., 1999) and service engineering (Shimomura and Tomiyama, 2005) have provided concrete methods. Especially in the research on service engineering, Shimomura and Tomiyama 
(2005) and Hara et al. (2009) developed modelling methods to represent both products and services that are available to manual services. However, these methods aim at designing services to fulfil customer values, and the values of service workers are not in their main focus. Hence, a new method is needed for modelling digital technology for service work to fulfil values of service workers.

\section{PROPOSED METHOD}

\subsection{Concept}

The modelling method proposed here is based on the integrative concept of participatory approach and systematic design proposed by Watanabe et al. (2013). In this concept called User-driven Product/Activity Design (UPAD), technological features and service activities at work are designed in parallel, through user participation, as shown in Figure 1. This concept aims at better integration of technology and service work, which is meaningful for this study. However, this concept does not provide concrete modelling methods to describe the design information. This study fulfils this gap by developing a modelling method for digital technology and service work.

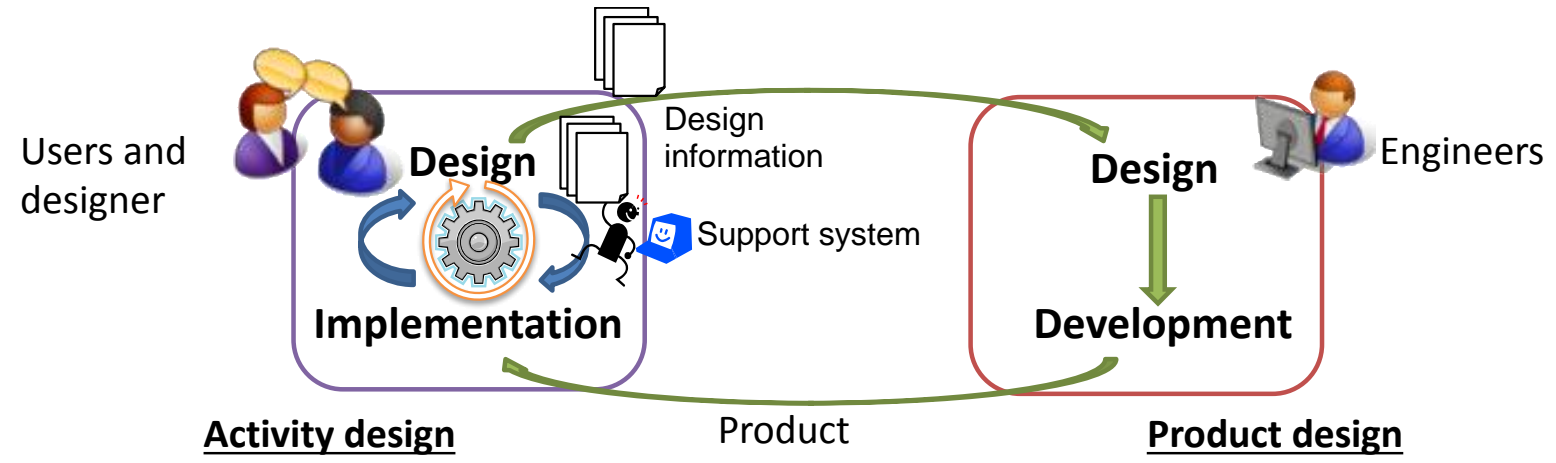

Figure 1. UPAD concept (based on Watanabe et al., 2013)

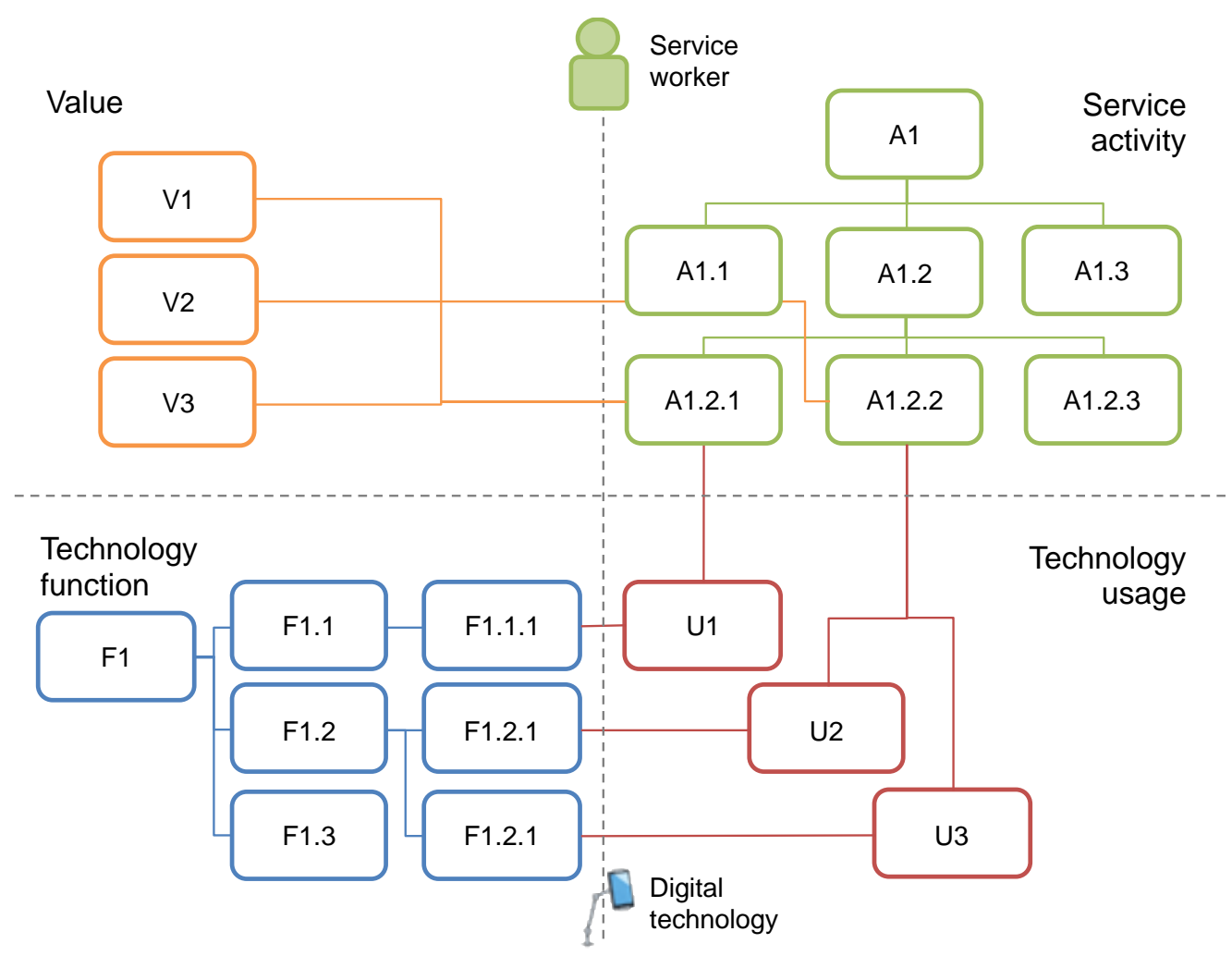

Figure 2. Modelling method 


\subsection{Modelling method}

The proposed method includes four modelling elements and their relations. Figure 2 describes their correlation. The represented models can be sequentially accumulated to confirm their change through the design process.

\subsubsection{Value}

The definition of value in this modelling method refers to Friedman et al. (2013), which is 'what a person or group of people consider important in life'. This definition covers a wide range of values including the aforementioned ones, such as wellbeing and ethical values of service workers. The value of a service worker is described as an element that corresponds to her/his activity. Value indicates the necessity of the corresponding activity and the technology function and usage connected through the service worker's activity. It can be described as qualitative / quantitative parameters corresponding to the requirements for assessing service work with the support of technologies.

\subsubsection{Service activity}

Service activities represent the activities that service workers perform in their service. They are described in structured form, such as a workflow and tree structure. A reference model to provide a basic structure of activities can be adopted for a coherent input. This study adopted Miwa et al.'s (2015) care task model, which represents activities of care professionals with three layers: service type, purpose/situation, and operation, as shown in Figure 3.

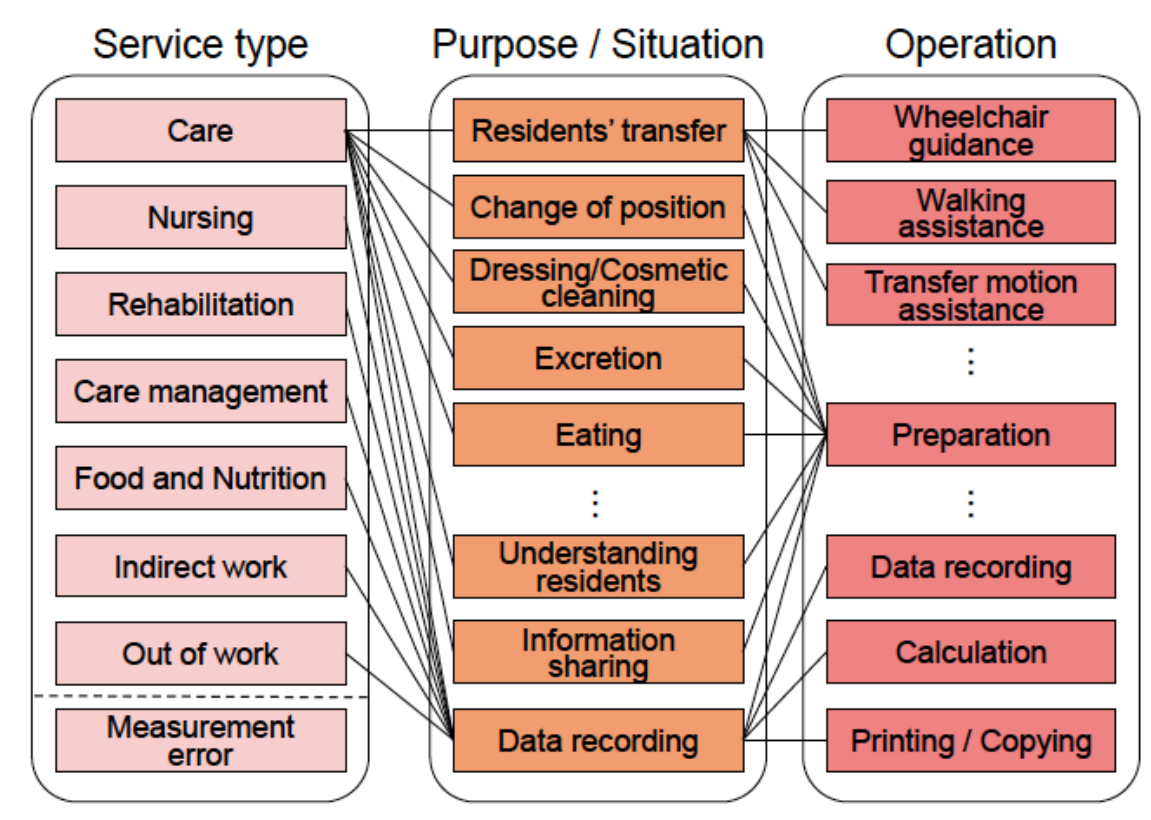

Figure 3. Care task model (Miwa et al., 2015)

\subsubsection{Technology function}

Technology functions describe the functional specification of the target digital technology, and are described using the functional tree structure (Tomiyama et al., 1993). The detailed functions are decomposed and described under a parent function. A technology function provides a general description of how technology works for its users.

\subsubsection{Technology usage}

Technology usage is an intermediate element that connects technology function and service activity. Technology usage embodies the associated technology function in a more concrete way corresponding with certain activity. For example, a patient lift has a function 'to lift up a person' and a caregiver has an activity 'to transfer an elderly person' when the usage of the lift can be 'to transfer an elderly person from a bed to a wheel chair'. 


\subsection{Modelling through participation}

The aforementioned challenges in digitalization require a deep understanding of service work and values of service workers. Participatory approach is effective for nurturing insights towards service work (Watanabe et al., 2013; Pérez García and Saffón López, 2018). For example, the participation of service workers in work study is important to precisely understand the current service work, values the target service worker perceives, and the challenges they confront. In addition, design workshop and a long-term user test, in which service workers participate are also effective approaches to evaluate the technology concept and to obtain effective use of the technology. Obtained data through the aforementioned studies will be used for the modelling of digital technologies and service work. In this study, designers are expected to mainly develop a model of digital technology and service work.

\section{CASE STUDY}

\subsection{Case description}

This study takes up a test case of a mobile application system for elderly care. This system was originally developed in Japan and then tested by Finnish caregivers. We applied this test case to evaluate the proposed method.

The tested system called DANCE (Fukuda et al., 2017) is a mobile communication application for information-sharing among care workers. Figure 4 shows the sample screenshots of DANCE. The aim of this system is to realize smooth and on-demand communication among care workers about customers, work situations and care environments. Care workers as the primary users of this system can share their information and knowledge on care with their colleagues, through texts, picture, voice, video, and emoji. This system was developed through co-design with care professionals in Japan.

In this study, three care professionals joined the test case. They worked for home-care services in a medium-sized city in Finland. They moved around and visited their customers' houses to provide care and support. They were out of their office for most of their working hours and regularly utilized a mobile system to record and share information (only with text) of their customers and care work.

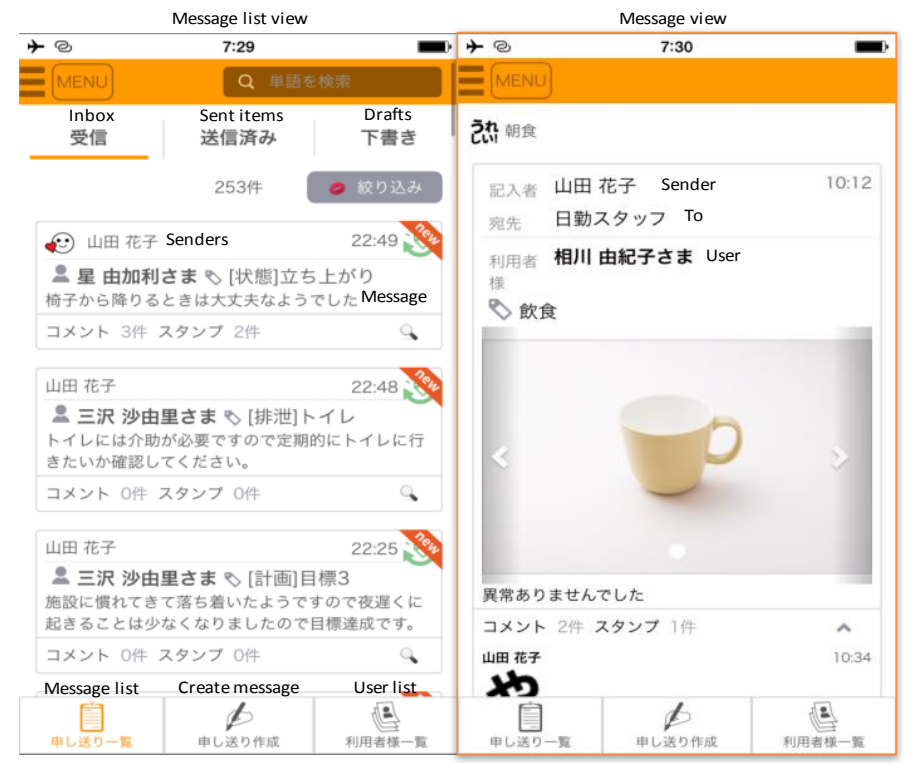

Figure 4. Sample screenshots of DANCE

\subsection{Research method}

This case study was conducted in the following process.

We conducted a test use of technologies as a workshop with the three participants. The workshop was held for $90 \mathrm{~min}$, in a meeting room of a welfare centre. For this workshop, DANCE translated into Finnish was used.

In this workshop, the participants were firstly explained about DANCE and its functionalities, and were asked to join two types of fictive use scenarios with sample data. The use scenarios were based on the key features of DANCE. The first scenario was to use photos, videos, and emojis to share 
information. The second scenario was to update customer information in the system. After the test, they were interviewed about how DANCE could be used for their work and could change it. The interview during the workshop was recorded and transcribed. The transcribed interview data and interview notes were mainly used for the modelling explained below. In addition, the input data to the system in the workshop and general information of home-care services in Finland were also used as supplement data.

We first extracted the participants' values at work and service activities from the workshop data. The activities were specified in the care task model, if it was possible and adequate. In addition, we developed a functional model of DANCE. Then we identified the technology usages and linked them with corresponding technology functions and service activities. Activities needed to realize the usages were also added in the service activity structure. Finally, further elements that would be needed or were beneficial for their service work were added in each structure and were correlated with the corresponding elements.

\section{RESULT}

The modelling result from this study is shown in Figure 5.

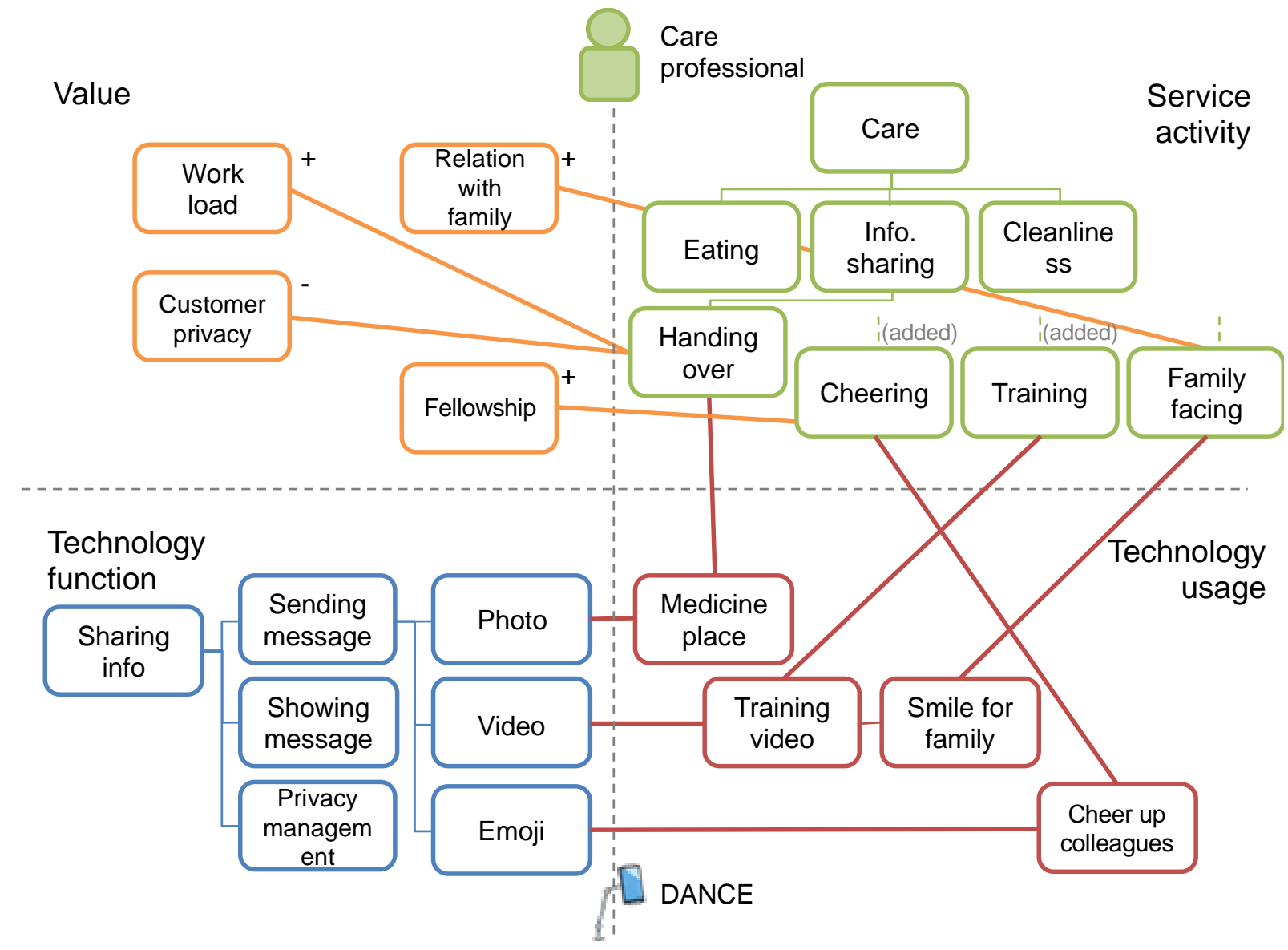

Figure 5. Modelling result

Various values were expressed or implied by the participants in the interview session. Work load describes their major challenges at work. The participants also cared about communication issues in relation with the other stakeholders, such as customer privacy in relation with photo and video, and the relation with family. We also created an activity diagram based on the interview result. In addition to direct care work, such as helping to eat and cleaning a room, indirect work including moving from a customer to another by car and information recording and sharing, was expressed. In addition, the original function diagram of DANCE was drawn. Figure 5 only shows the communication function which was taken up in the workshop.

Figure 5 also shows several potential usages of photo, video, and emoji, which were expressed in the workshop. The impact of service activities and correlated technology usages and functions to the 
corresponding value is described with ' + ' mark as positive and '-' mark as negative. As the usage of video, making and sharing a training video, such as how to use a kidney catheter, were suggested. Sharing the customer's smile with her/his family using video was also suggested, which would be effective to make better relationship with family. An interesting usage of photo is to share the information of hidden medicines' place at the customer's house. This is needed to prevent an overdose by the elderly, especially with memory problems. They had to share this information with text, which was difficult. These usages are connected to related functions and activities. For example, the usage 'medicine place' is connected to the function 'photo' and the activity 'handing over.' Another interesting idea of emoji usage is to cheer-up colleagues. Before proposing this idea, they mainly mentioned their individualized work environments. However, this idea highlighted a new activity 'cheering' which is not in the original activity diagram, and another value 'fellowship' with colleagues.

The participants' concern about these functions is customer privacy. According to them, it is allowed to share photos as long as the purposes and members to share are agreed with customers. However, it is difficult to manage such information, so they did not regularly share it. When they would use photos more with DANCE in their work, they should be required to obtain consent precisely and to manage privacy information. These will affect their work load negatively. Therefore, a technological function such as privacy management will become valuable for users.

\section{DISCUSSION}

The proposed modelling method describes various values ranging from ergonomic value to ethical value. It is beneficial to show which activities at work and correlated technology functions and usages affect the values of service workers. The evaluation of impact to values would be meaningful for improving the design of digital technology and service work. This modelling result also illustrated conflicting values through technology integration. The proposed modelling method does not provide a means to solve such conflicts, but some decision-making support methods could be considered to solve represented conflicts.

It is also worth mentioning that the participants came up with various usages of DANCE based on their work experiences. This is exactly why the participatory approach is important for better integration of digital technology into service work. The workshop to extract usages and to represent them in the systematic modelling scheme proposed in this study was also meaningful to specify the required technology functions and expected work in a service field.

This modelling method can describe how the model changed through the design process. By developing these models, it could become easier to share the ideas of how the technology specification and work activities were coordinated, with other workers, though further study is needed for verification.

The participants may even notice and claim different values they did not consider in advance, such as 'fellowship' in this workshop. By accumulating the collected data in the design process, the required technologies and service work will become more matured. Unlike the ordinary co-design approach, this method provides a structured information of technology functions, which will be useful for the later technology development phase.

This method would be meaningful for specifying different requirements and usages under different work culture. This study does not provide a concrete remark for international comparison, but this could be considered as future research.

This paper is based on a single small case study, which is a limitation of this study. For improving and establishing the proposed method, we need more case studies with different types of technologies. In addition, a more systematic design process with different types of methods needs to be considered to obtain deeper insights and make a model using the proposed modelling method. The participation by service workers was also limited in this study. A long-term field study with larger number of participants needs to be considered for future study.

\section{CONCLUSION}

This paper proposes a modelling method based on the integrative concept of systematic design and participatory approach. This method was developed to tackle the challenges in development and 
implementation of digital technologies for service work, which are the diverse values for service workers and changing service work through technology implementation.

The proposed method can describe technology functions and usages, as well as values and activities of service workers. They provide structured representation, which expresses how technology and care workers interact at service work. Through the test case with care professionals of home-care services, diverse values of care workers are expressed in a way to correlate with their work and technology functions. In addition, change in service work in relation with the technology function and usage was described with the modelling method, which would be helpful for a better understanding of the impact of technologies. Both technology developers and users can share their view using such a modelling method.

As future work, the modelling method should be used for various digital technologies such as AI and robotics. In addition, technology implementation would affect multiple stakeholders. In the case of elderly care, the elderly as customers and their families would be affected by the mobile system tested in this study. The modelling method that takes care of multiple stakeholders should be considered in the future.

\section{REFERENCES}

Akaka M. A., Vargo S. L. and Lusch R. F. (2013), “The complexity of context: A service ecosystems approach for international marketing", Journal of Marketing Research, Vol. 21 No. 4, pp. 1-20.

Bue Lintho, O. and Nes Begnum, M. E. (2018), "Towards inclusive service design in the digital society: current practices and future recommendations", NordDesign 2018, Linköping, Sweden, 14th-17th August 2018.

Calvo, R. A. and Peters, D. (2015), Positive Computing: Technology for Wellbeing and Human Potential, MIT Press, Cambridge, MA.

D’Emidio, T., Dorton, D. and Duncan, E. (2015), "Service Innovation in a Digital World", McKinsey Quarterly, Available at: https://www.mckinsey.com/business-functions/operations/our-insights/service-innovation-ina-digital-world (3.12.2018).

Djellal, F. and Gallouj, F. (2006), "Innovation in care services for the elderly", The Service Industries Journal, Vol. 26 No. 3, pp. 303-327. https://doi.org/10.1080/02642060600570943

Edvardsson, B. and Olsson, J. (1996), "Key concepts for new service development”, The Service Industries Journal, Vol. 16 No. 2, pp. 140-164.

European Agency for Safety and Health at Work (EU-OSHA) (2013), Well-being at Work: Creating a Positive Work Environment -Literature Review, Publications Office of the European Union, Luxembourg.

Fitzsimmons, J. and Fitzsimmons, M.J. (1999), New service development: creating memorable experiences, Sage Publications, Thousand Oaks.

Friedman, B., Kahn, P. H., Borning, A. and Huldtgren, A. (2013), "Value sensitive design and information systems", In: Doorn N., Schuurbiers D., van de Poel I. and Gorman M. (Eds.), Early engagement and new technologies: Opening up the laboratory. Philosophy of Engineering and Technology, Vol. 16, Springer, Dordrecht, pp. 55-95. https://doi.org/10.1007/978-94-007-7844-3_4

Fukuda, K., Nakajima, M., Nishimura, S. and Nishimura, T. (2017), "Non-Routine Knowledge Sharing in Elderly Care-Facility for Better Services", The 18th European Conference on Knowledge Management, Barcelona, Spain, 7-8 September 2017, pp. 326-333.

Future of Life Institute (2017), Asilomar AI Principles, Available at: https://futureoflife.org/ai-principles/ (13.12.2018)

Greenbaum, J. and Kyng, M. (1991), Design at Work: Cooperative Design of Computer Systems, Erlbaum, Hillsdale, NJ.

Goedkoop, M.J., van Halen, J.G., te Riele, H. and Rommens, P.J.M. (1999), Product Service Systems: Ecological and Economic Basics, Dutch Ministries of Environment (VROM) and Economic Affairs (EZ), Hague, Netherlands.

Hara, T., Arai, T. and Shimomura, Y. (2009), “A CAD system for service innovation: Integrated representation of function, service activity, and product behaviour”, Journal of Engineering Design, Vol. 20 No. 4, pp. 367-388.

International Labour Organizations (ILO) (2018), Workplace Well-being, Available at: https://www.ilo.org/safework/areasofwork/workplace-health-promotion-and-wellbeing/WCMS_118396/lang--en/index.htm (4 December 2018)

Leikas, J. (2014), Ikäteknologia, NewPrint Oy, Raisio.

Miwa, H., Watanabe, K., Fukuhara, T., Nakajima, M. and Nishimura, T. (2015), "Measurement and description of nursing-care service process", Transactions of the JSME, Vol. 81 No. 822, (in Japanese). https://doi.org/10.1299/transjsme.14-00207

Pérez García, M. and Saffón López, S. (2018), "Meet AURA: A Study on how Iterative Design Methodologies and User Participation Help Improve Results in Technology Driven Pilot Projects", DESIGN 2018 15th 
International Design Conference, Dubrovnik, Croatia, 21-24 May 2018, pp. 1289-1300. https://doi.org/10.21278/idc.2018.0423

Pot, F. D. (2017), “Workplace Innovation and Wellbeing at Work”, In: Oeij P. R. A., Rus D. and Pot F. D. (Eds.), Workplace Innovation Theory, Research and Practice, Springer, Cham, pp. 95-110.

Salvendy, G. (2012), Handbook of Human Factors and Ergonomics, John Wiley \& Sons, Hoboken, NJ.

Shimomura, Y. and Tomiyama, T. (2005), "Service modeling for service engineering", In: Arai E., Kimura F. and Shirase K. (Eds.), Knowledge and Skill Chains in Engineering and Manufacturing, Springer, New York, NY, pp. 31-38.

Siegel, C., Hochgatterer, A. and Dorner, T.E. (2014), “Contributions of ambient assisted living for health and quality of life in the elderly and care services - a qualitative analysis from the experts' perspective of care service professionals", BMC Geriatrics, Vol. 14 No. 122, https://doi.org/10.1186/1471-2318-14-112.

Stahl, B.C. and Wright, D. (2018), "Ethics and privacy in AI and Big Data", IEEE Security \& Privacy, Vol. 16 No. 3, pp. 26-33. http://doi.ieeecomputersociety.org/10.1109/MSP.2018.2701164.

Stickdorn, M. and Schneider, J. (2012), This Is Service Design Thinking: Basics, Tools, Cases, Wiley, Hoboken, NJ.

Tomiyama, T., Umeda, Y. and Yoshikawa, H. (1993), “A CAD for functional design”, CIRP AnnalsManufacturing Technology, Vol. 42 No. 1, pp. 143-146. https://doi.org/10.1016/S0007-8506(07)62412-3.

Watanabe, K., Fukuhara, T., Miwa, H. and Nishimura, T. (2013), “A unified approach for systematic and participatory design", 19th International Conference on Engineering Design (ICED13), Seoul, Korea, 1922 August 2013.

Watanabe, K., Fukuda, K. and Nishimura, T. (2015), “A technology-assisted design methodology for employeedriven innovation in services”, Technology Innovation Management Review, Vol. 5 No. 2, pp. 6-14.

Watanabe, K., Hyytinen, K. and Tuovila, T. (2018), "Challenges in Integrating Assistive Technologies into Elderly-Care Services: Comparative Study between Japan and Finland”, European Review of Service Economics and Management, No. 6, pp. 97-122.

\section{ACKNOWLEDGEMENTS}

We are deeply grateful to the participants of this study. We also thank Ms. Mari Ylikauppila, Ms. Hanna Lammi and Dr. Marketta Niemelä for supporting this study. This study is supported by JST, Strategic International Collaborative Research Program, SICORP. This paper is based on results obtained from a project commissioned by the New Energy and Industrial Technology Development Organization (NEDO), and was also partly supported by Japanese METI's Robotic Care Equipment Development and Introduction Project. 